\title{
A IMPORTÂNCIA DO MONITORAMENTO DE ÁGUAS SUBTERRÂNEAS NO ABASTECIMENTO PÚBLICO DE ÁGUA: MUNICÍPIO DE CAMPO GRANDE, MS
}

\author{
Liliane Maia Tcacenco-Manzano ${ }^{1}$; Camila de Vasconcelos Müller Athayde ${ }^{2}$; Luiz Eduardo \\ Mantovani ${ }^{3}$ \& Ernani Francisco da Rosa Filho ${ }^{4}$
}

Resumo - O monitoramento de águas subterrâneas é fundamental devido ao fato da água ser um recurso limitado, além de vulnerável à contaminações por ações e condições antrópicas. Com o aumento da demanda de água para o abastecimento público de grandes cidades, faz-se necessário um monitoramento efetivo, tanto qualitativo quanto quantitativo, dos poços tubulares profundos. Como alternativa às fontes superficiais de abastecimento, os poços tubulares profundos no município de Campo Grande, MS, totalizam 40 \% do abastecimento público de água. Com isso, é necessário o acompanhamento constante dos padrões hidrodinâmicos dos poços tubulares, como profundidades do nível estático, profundidade do nível dinâmico, vazões, capacidades específicas, associados ainda, à análises hidroquímicas. Com as análises desses parâmetros, medidas preventivas podem ser adotadas, sendo elas: evitar a superexplotação dos sistemas aquíferos; limpeza de filtros obstruídos, prolongando a vida útil do poço; desativação de poços pela ocorrência de contaminante, como exemplo, água extraída por poços tubulares com teores elevados de nitrato ou desativação por produção de areia, inviabilizando a produção. Assim, o monitoramento preventivo dos poços tubulares profundos é necessário para a manutenção da quantidade e qualidade de água, visando o abastecimento contínuo do município e preservando o tempo de vida útil dos poços.

\begin{abstract}
Monitoring of groundwater is crucial due to the fact that water is a limited resource, and vulnerable to contamination by anthropogenic actions and conditions. With the increasing demand of water for public supply of large cities, it is necessary an effective monitoring both qualitative and quantitative, production of deep wells. As an alternative to surface water sources, the deep wells in the city of Campo Grande, MS, totaling $40 \%$ of the public water supply. Thus, the constant monitoring of hydrodynamic patterns of wells is necessary, as the depths of static level, the
\end{abstract}

\footnotetext{
${ }^{1}$ LPH- Laboratório de Pesquisas Hidrogeológicas - Setor de Ciências da Terra - Departamento de Geologia, Universidade Federal do Paraná, UFPRCentro Politécnico - Jardim das Américas - 81990-551 (41) 91127644, lilianemaia@gmail.com

2 LPH- Laboratório de Pesquisas Hidrogeológicas - Setor de Ciências da Terra - Departamento de Geologia, Universidade Federal do Paraná, UFPRCentro Politécnico - Jardim das Américas - 81990-551 , (41) 33613136, camilavmuller@ufpr.br

${ }^{3}$ LPH- Laboratório de Pesquisas Hidrogeológicas - Setor de Ciências da Terra - Departamento de Geologia, Universidade Federal do Paraná, UFPRCentro Politécnico - Jardim das Américas - 81990-551 , (41)33613385, lem@ufpr.br

${ }^{4}$ LPH- Laboratório de Pesquisas Hidrogeológicas - Setor de Ciências da Terra - Departamento de Geologia, Universidade Federal do Paraná, UFPRCentro Politécnico - Jardim das Américas - 81990-551 , (41) 33613385, ernani@ufpr.br
} 
dynamic level depth, flow, specific capabilities associated also to hydrochemical analysis. With the analysis of these parameters, preventive measures can be adopted, namely: avoid overexploitation of aquifers; cleaning of clogged filters, extending the life of the well; deactivation by contaminants, for example, water extracted by wells with high nitrate or sand production by deactivation levels, preventing production. Thus, the preventive monitoring of deep wells is necessary to maintain the quantity and quality of water, targeting the continuous supply of the city and preserving the useful life of the wells.

Palavras-Chave: Monitoramento. Poços tubulares profundos. Campo Grande

\section{1- INTRODUÇÃo}

O monitoramento preventivo dos parâmetros hidrodinâmicos e hidroquímicos de poços tubulares profundos é importante para o aumento do tempo de vida útil de produção de um poço, associado a quantidade e qualidade da água produzida por este. Indícios como rebaixamento de níveis ao longo do tempo, produção de areia e alterações de padrões hidroquímicos podem sugerir que o poço está com sua operação comprometida. Quando se trata de abastecimento público, a empresa concessionária responsável pelo abastecimento deve prezar pela eficácia, eficiência e regularidade dos serviços prestados, além de garantir o acesso a água potável a sua população. O município de Campo Grande, MS, administrado pela Concessionária Águas Guariroba S.A., possui aproximadamente 150 poços tubulares profundos em operação, o que garante 40\% do abastecimento de água no munícipio, complementando as formas de abastecimento por captação superficial. Os primeiros poços, perfurados na década de 1970, e alguns em operação até hoje, contemplam um período de 30 anos de dados para monitoramento, e fornecem assim, dados para interpretações sobre o comportamento local dos sistemas aquíferos.

\section{2- OBJETIVOS}

O monitoramento dos dados dos aquíferos é um processo que engloba a coleta, armazenamento, tratamento e interpretação de dados. Os parâmetros analisados e que resultaram no produto desse trabalho são : profundidades dos níveis estático, profundidades dos níveis dinâmicos, vazões, rebaixamentos, capacidades específicas e análises físico químicas. Assim, o objetivo desse trabalho é mostrar a eficácia do monitoramento preventivo de poços tubulares profundos, visando 
as melhores condições para explotação da água subterrânea, de forma a gerar uma maior vida útil de produção dos poços, afim de suprir a demanda do abastecimento público contínuo.

\section{3- CONTEXTO GEOLÓGICO REGIONAL}

O município de Campo Grande, capital do Mato Grosso do Sul, localiza-se no centro oeste brasileiro. A área de estudo desse trabalho abrange poços tubulares profundos localizados na área urbana do município (Figura 1).

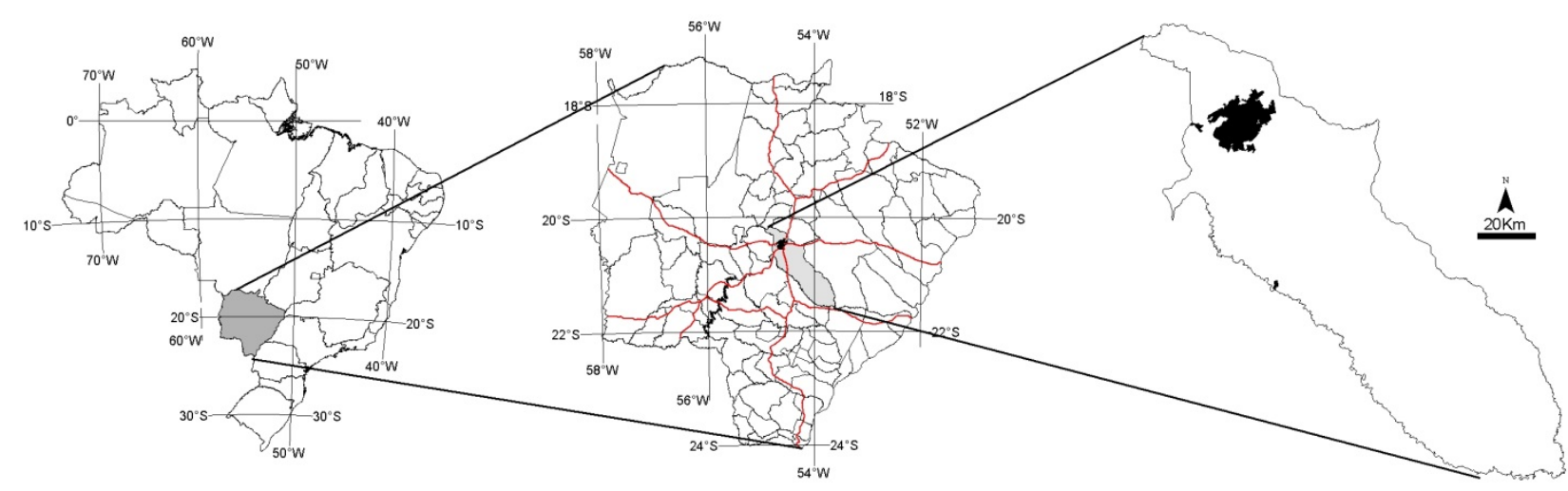

Figura 1: Mapa de localização da área urbana do município de Campo Grande, MS

O contexto geológico regional da área de estudo está inserida na Bacia Sedimentar do Paraná e na Bacia Bauru. Segundo Milani et al, 2007; a Bacia Sedimentar do Paraná é uma bacia intracratrônica, situada no centro leste da América do Sul, e inclui parte dos territórios do Brasil, Argentina, Uruguai, e Paraguai, podendo alcançar uma área de aproximadamente $1.5000 .000 \mathrm{Km}^{2}$. Em território brasileiro compreende aproximadamente $1.100 .000 \mathrm{Km}^{2}$. Os estados em que afloram rochas da Bacia do Sedimentar do Paraná são: Rio Grande do Sul, Santa Catarina, Paraná, São Paulo, Minas Gerais, Mato Grosso do Sul, Mato Grosso e Goiás (Figura 2). 


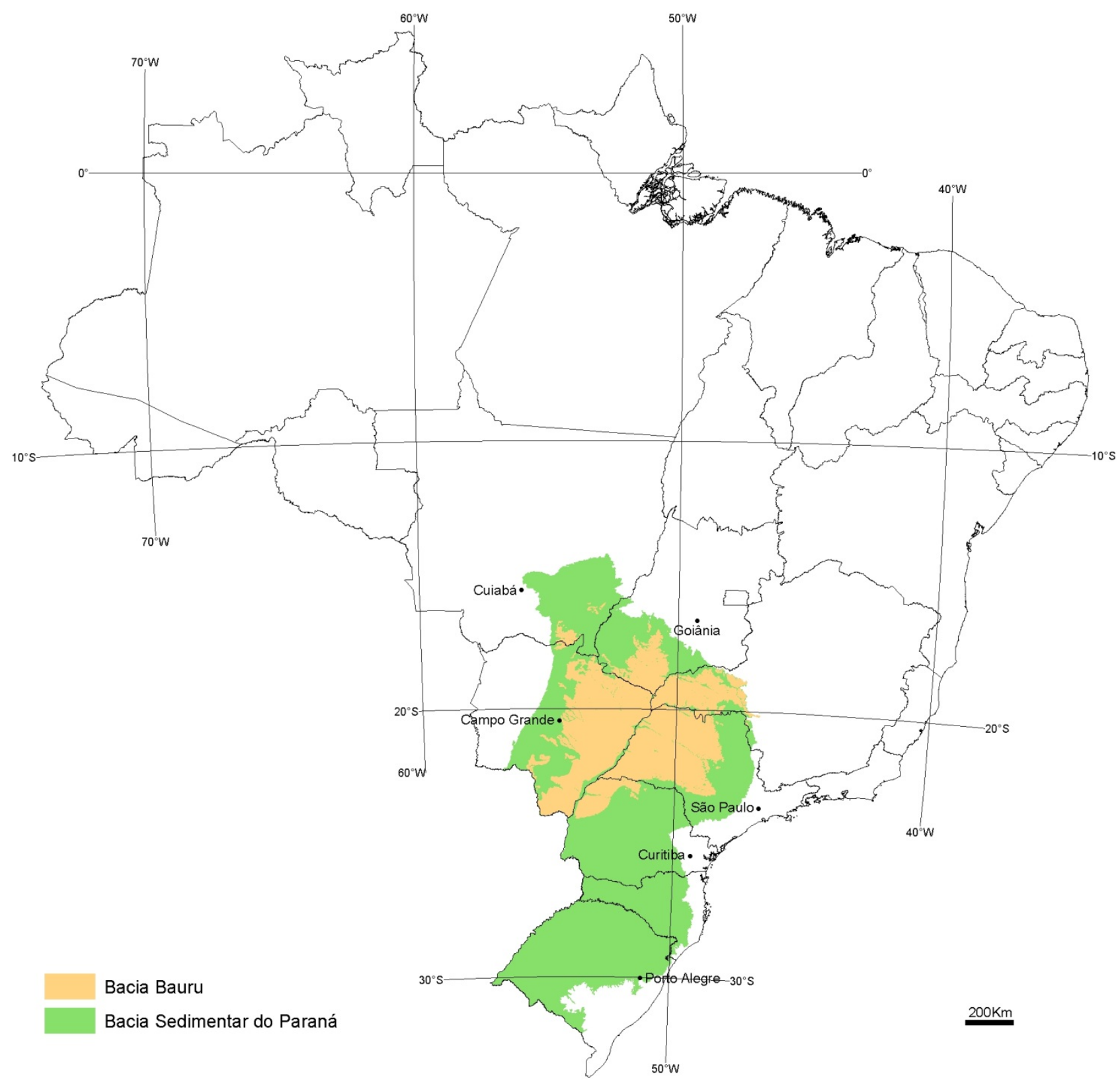

Figura 2: Mapa das localizações das bacias sedimentares do Paraná e Bauru, em território nacional.

O registro tectono-sedimentar da Bacia Sedimentar do Paraná compreende idades entre o Meso Ordoviciano ao Eo Cretáceo. Sua espessura sedimentar pode chegar a 7.000 metros na parte central da bacia, representada pela calha do rio Paraná (Milani, et al, 2007). O pacote sedimentar da bacia é subdividido em supersequências relacionadas a diferentes tempos e mecanismos de subsidência e denominadas a seguir:

1. Seqüência Ordovicio-Siluriana, representada pelo Grupo Rio Ivaí;

2. Seqüência Devoniana, representada pelo Grupo Paraná;

3. Seqüência Neocarbonífera-Permiana, correspondendo aos grupos Itararé, Guatá e Passa Dois; 
4. Seqüência Triássica, presente somente na região sul da bacia (Grupo Rosário do Sul) e em São Paulo (Formação Pirambóia);

5. Seqüência Jurássica-Eocretáceo, representada pelo Grupo São Bento;

6. Seqüência Neocretácea, representada pelos grupos Caiuá e Bauru.

Porém, há estudos em que a sequência Neocretácea, representada pelos grupos Caiuá e Bauru, é assumida como uma unidade tectônica distinta da bacia sedimentar do Paraná, (Menegazzo et al 2016, Fernandes e Coimbra, 1992; Fúlfaro e Perinotto, 1996; Fernandes e Coimbra, 1996, 2000; Riccomini, 1997) e denominada Bacia Bauru. Essa bacia sobrepõe-se as rochas vulcânicas da Formação Serra Geral e é representada por uma área de $379.362 \mathrm{~km}^{2}$, quase que em sua totalidade no Brasil (Menegazzo, 2016). Segundo Fernandes, 1998 a Bacia Bauru se formou por subsidência termo mecânica, sobreposta as rochas vulcânicas da Formação Serra Geral. Segundo Menegazzo, et al 2016, a bacia Bauru é uma resposta a carga supracrustal e deflexão flexural resultantes do início da orogenia andina, durante a migração para oeste da Placa Sul-Americana e a subducção da Placa Farallon. Ainda nesse trabalho, os autores fazem referências a Bacia Bauru fazer parte da província back-bulge de um retroarc foreland system, desenvolvido no oeste da América do Sul.

Na área de estudo desse trabalho são estudadas as sequências Jurassica EoCretáceo, representados pelo magmatismo da Formação Serra Geral e a Bacia Bauru, assinalada na carta estratigráfica da Bacia Sedimentar do Paraná como uma sequência Neocretácea. 


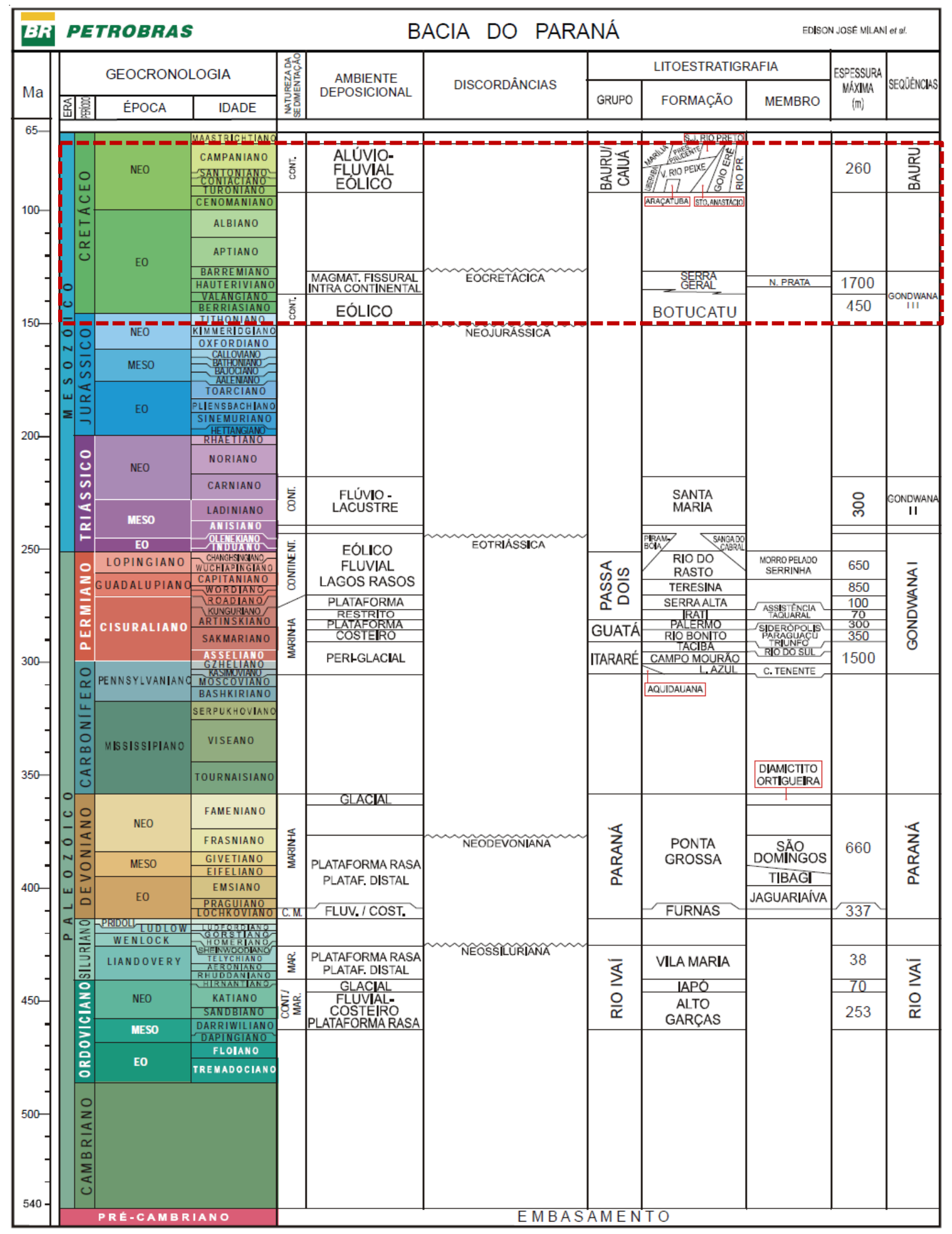

Figura 3: Carta estratigráfica da Bacia Sedimentar do Paraná (Milani, et. Al., 2007), com os intervalos estudados assinalados.

\section{4- CONTEXTO GEOLÓGICO E HIDROGEOLÓGICO LOCAL}


A geologia local da área de estudo é representada pelas formações Botucatu, Serra Geral e Grupo Caiuá Indiviso. A Formação Serra Geral aflora em aproximadamente 90\% do município de Campo Grande, sendo os 10\% restantes aflorando o Grupo Caiuá indiviso.

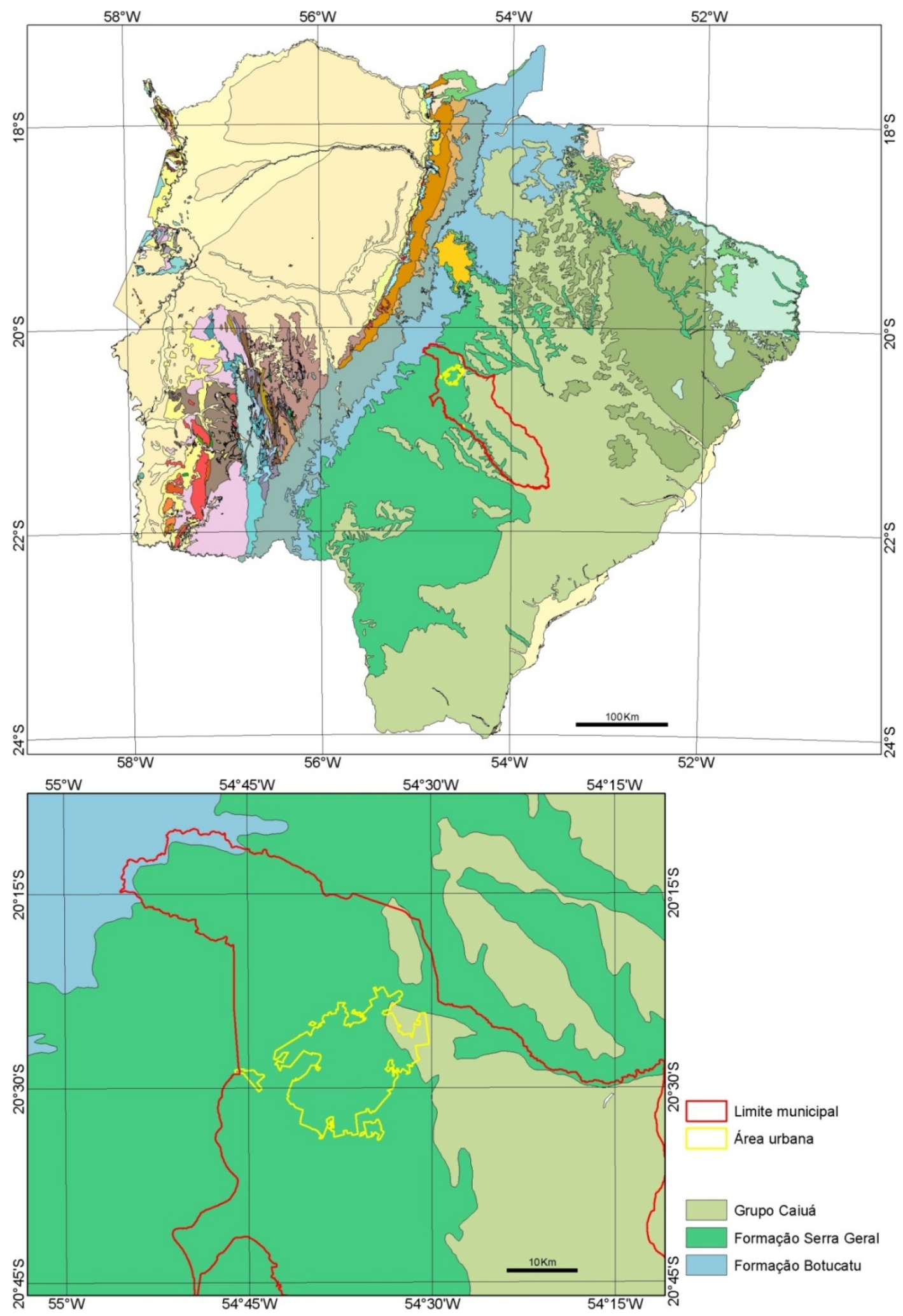

Figura 4: Mapa geológico do estado do Mato Grosso do Sul, com detalhe do limite municipal e da área urbana de Campo Grande. Modificado de CPRM, 2006. 
O contexto hidrogeológico é representado por três sistemas aquíferos: Sistema Aquífero Guarani (Formação Botucatu) que é uma unidade hidrogeológica confinada, sedimentar, porosa e permeável; Sistema Aquífero Serra Geral é um aquífero sotoposto pelo Sistema Aquífero BauruCaiuá na parte nordeste do município e aflorante no restante do município, fraturado e descontínuo e o Sistema Aquífero Bauru-Caiuá, uma unidade hidrogeológica contínua e livre, sedimentar, porosa e permeável.

\section{5- MATERIAIS E MÉTODOS}

O acervo histórico no município de Campo Grande comtempla aproximadamente 150 poços em operação. Esses poços são denominados da forma a seguir, por uma nomenclatura interna da empresa:

Pocinhos: poços perfurados com objetivo de captação de água do sistema aquífero BauruCaiuá, com aproximadamento 80 metros de profundidade, revestimento em 8” (oito polegadas) e vazões médias de $40 \mathrm{~m}^{3} \mathrm{~h}^{-1}$.

$\checkmark$ Poços: poços perfurados com objetivo de captação de água do sistema aquífero Serra Geral, com até 150 metros de profundidade, com perfuração de 8” (oito polegadas), sem revestimento e vazões médias de $50 \mathrm{~m}^{3} \mathrm{~h}^{-1}$.

$\checkmark$ Poços de alto rendimento (PAR): poços de até 250 metros, revestimento em 10” (dez polegadas) e vazões de até $100 \mathrm{~m}^{3} \mathrm{~h}^{-1}$, visando a captação de água do sistema aquífero Guarani.

$\checkmark$ Poções: poços com revestimento de 12” (doze polegadas), profundidades de perfuração acima de 250 metros e vazão variável entre 150 a $300 \mathrm{~m}^{3} \mathrm{~h}^{-1}$, visando a captação de água do sistema aquífero Guarani.

A medição de profundidades de níveis estáticos e dinâmicos, além de vazões e cálculo de capacidades específicas é realizada uma vez por semestre, na rotina normal de trabalho da empresa. As medições de níveis são realizadas através de medidor elétrico de nível de água, colocado no tubo guia de 1⁄2”, em PVC, quando um poço está parado. Com isso é possível a aferição do nível estático, em repouso, com intervalo de 4 a 6 horas do poço estar sem funcionamento. As medições de vazões são feitas através de hidrômetros instalados no cavalete do poço (Figura 5). 


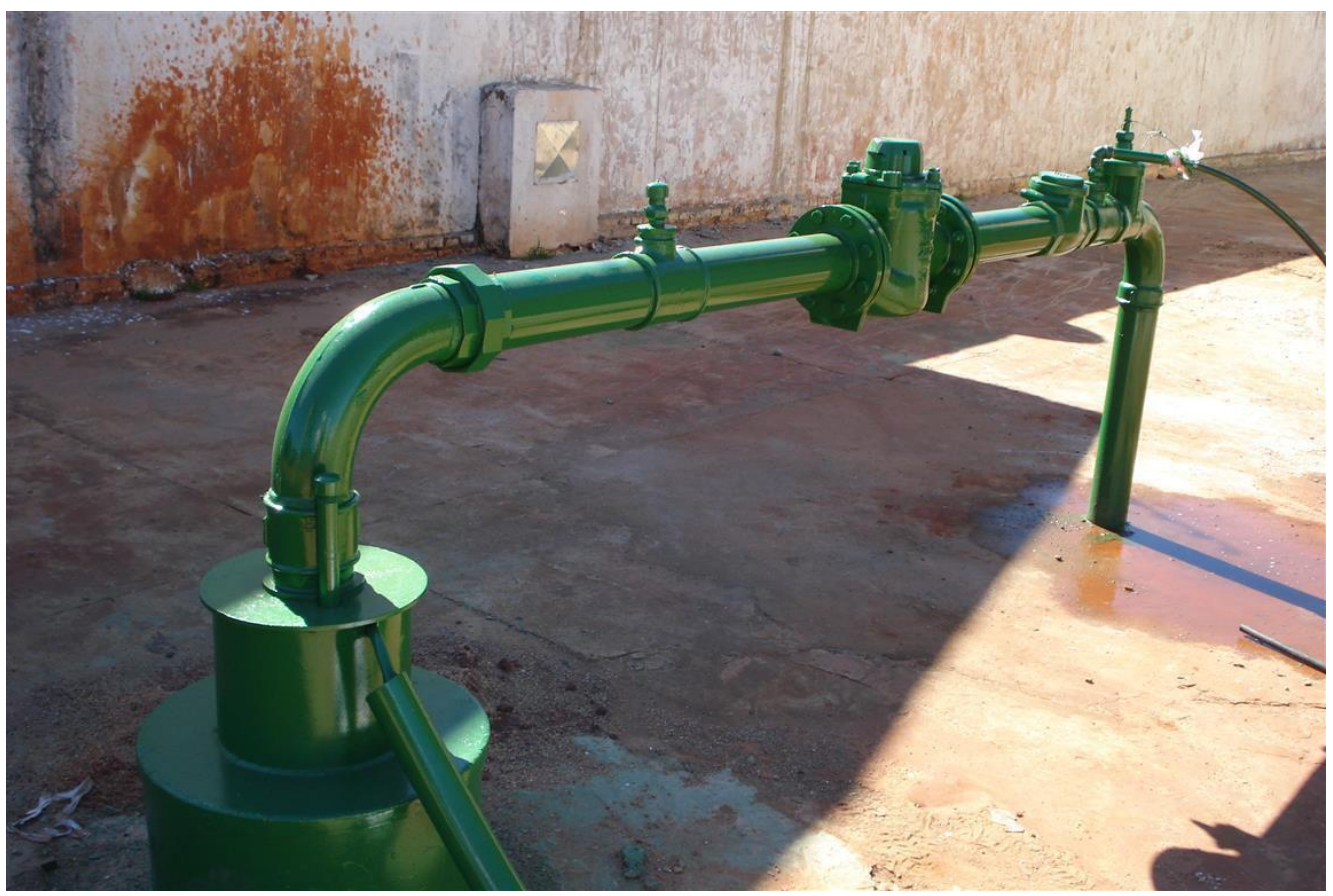

Figura 5: Foto de poço tubular profundo com tubo guia de 1/2” para aferição de níveis, hidrômetro e ponto de coleta de água.

Além dos parâmetros hidrodinâmicos, são coletadas amostras de análises de águas semestralmente para envio à Agência de regulação de água do município. Com isso, o monitoramento dos padrões físico-químicos podem facilmente ser associados com o monitoramento dos padrões hidrodinâmicos.

Para municípios nos quais o saneamento básico é recente, e que por muito tempo não havia coleta de esgoto, o monitoramento de alguns parâmetros físico-quimicos é imprescindível. Como exemplo, podemos citar a contaminação de águas subterrâneas por nitrato, oriundo de contaminações por fossas sépticas. Além disso, nessas medições, podemos monitorar pH, manganês e ferro, além de cloretos e sólidos totais dissolvidos.

Para esse estudo foram detectados alguns poços que, devido ao monitoramento constante de dados, apresentaram indícios de problemas.

\section{6- RESULTADOS}

As manutenções preventivas dos poços tubulares profundos são realizadas semestralmente. Nela, são feitas as seguintes medições: parâmetros elétricos de tensão e corrente do equipamento moto-bomba submerso e, também, os parâmetros hidrodinâmicos dos poços: profundidade do nível estático, profundidade do nível dinâmico. Além disso, são realizadas a analise in natura de cada poço. Com a interpretação desses dados de monitoramento ao longo do tempo é possível observar a 
tendência do poço a manter uma vazão e níveis constantes ou ter alguma perda significativa de sua capacidade específica.

Os chamados pocinhos tem sido acompanhados com maior ênfase, devido a ser um projeto recente de perfuração. Com isso, foram apontados alguns problemas que só puderam ser acompanhados devido a um monitoramento preventivo de dados:

1) Perda de vazão em relação a vazão de teste: isso ocorre pelo fato do teste de vazão ter sido feito em fase única, não ter tido escalonamento e assim, ter apresentado um valor de vazão de teste superior ao valor de vazão de produção real do poço.

Tabela 1: Acompanhamento de poço perfurado no ano de 2011, com valor superestimado de vazão no teste.

\begin{tabular}{|c|c|c|c|c|c|}
\hline Ano & $\begin{array}{c}\text { Nível } \\
\text { Estático } \\
(\mathrm{m})\end{array}$ & $\begin{array}{c}\text { Nível } \\
\text { Dinâmico } \\
(\mathrm{m})\end{array}$ & $\begin{array}{c}\text { Rebaixamento } \\
(\mathrm{m})\end{array}$ & $\begin{array}{c}\text { Vazão } \\
\left(\mathrm{m}^{3} \mathrm{~h}^{-1}\right)\end{array}$ & $\begin{array}{c}\text { Capacidade } \\
\text { específica } \\
\left(\mathrm{m}^{3} \mathrm{~h}^{-1} \mathrm{~m}^{-1}\right)\end{array}$ \\
\hline 2011 & 45 & 71 & 26 & 85,5 & 3,29 \\
\hline 2012 & 51 & 72,5 & 21,5 & 65 & 3,03 \\
\hline 2013 & 54,6 & 66 & 11,4 & 44,8 & 3,92 \\
\hline 2014 & 50 & 61 & 11 & 28,2 & 2,56 \\
\hline 2015 & 50 & 60,5 & 10,5 & 28,2 & 2,68 \\
\hline
\end{tabular}

O poço da tabela acima, projetado para explotar água do sistema aquífero BauruCaiuá, embora com um vazão de teste de $85 \mathrm{~m}^{3} \mathrm{~h}^{-1}$, opera hoje com um terço dessa capacidade.

2) Limpeza preventiva de poços tubulares: foi realizado em alguns pocinhos que estavam perdendo vazão ao longo do tempo, uma limpeza preventiva, com utilização de compressor, produto químico, pistoneamento e desinfecção do poço, obtendo uma pequena melhora na vazão. No começo de 2015 houve a limpeza do poço, resultante em uma melhora de vazão. 
Tabela 2: Melhora na vazão de captação de água do poço tubular profundo devido a limpeza preventiva.

\begin{tabular}{|c|c|c|c|c|c|}
\hline Ano & $\begin{array}{c}\text { Nível } \\
\text { Estático } \\
(\mathrm{m})\end{array}$ & $\begin{array}{c}\text { Nível } \\
\text { Dinâmico } \\
(\mathrm{m})\end{array}$ & $\begin{array}{c}\text { Rebaixamento } \\
(\mathrm{m})\end{array}$ & $\begin{array}{c}\text { Vazão } \\
\left(\mathrm{m}^{3} \mathrm{~h}^{-1}\right)\end{array}$ & $\begin{array}{c}\text { Capacidade } \\
\text { específica } \\
\left(\mathrm{m}^{3} \mathrm{~h}^{-1} \mathrm{~m}^{-1}\right)\end{array}$ \\
\hline 2010 & 50 & 63 & 13 & 42 & 3,23 \\
\hline 2011 & 50 & 64,5 & 14,5 & 39,4 & 2,71 \\
\hline 2012 & 49,3 & 61,8 & 12,5 & 36,3 & 2,90 \\
\hline 2013 & 49,4 & 62 & 12,6 & 36,6 & 2,90 \\
\hline 2014 & 49,5 & 59 & 9,5 & 30 & 3,15 \\
\hline 2015 & 48,7 & 64 & 15,3 & 36 & 2,35 \\
\hline 2016 & 51 & 57 & 6 & 36 & 6 \\
\hline
\end{tabular}

3) Produção de areia: os poços que produziram areia foram poços preenchidos com pré-filtro super dimensionado, carreando material da formação geológica para dentro do poço. Em alguns desses poços foi interpretado que possívelmente houve a saturação do pré-filtro, com muita partícula fina da formação geológica e assim, significativa produção de areia. Isso acaba comprometendo o conjunto moto-bomba submersa, promovendo seu desgaste e inviabilizando o funcionamento do poço.

4) Poços perfurados visando captação de água do sistema aquífero Serra Geral tem apresentado vazões e níveis de exploração constantes, não havendo perda de capacidade específica ao longo do tempo.

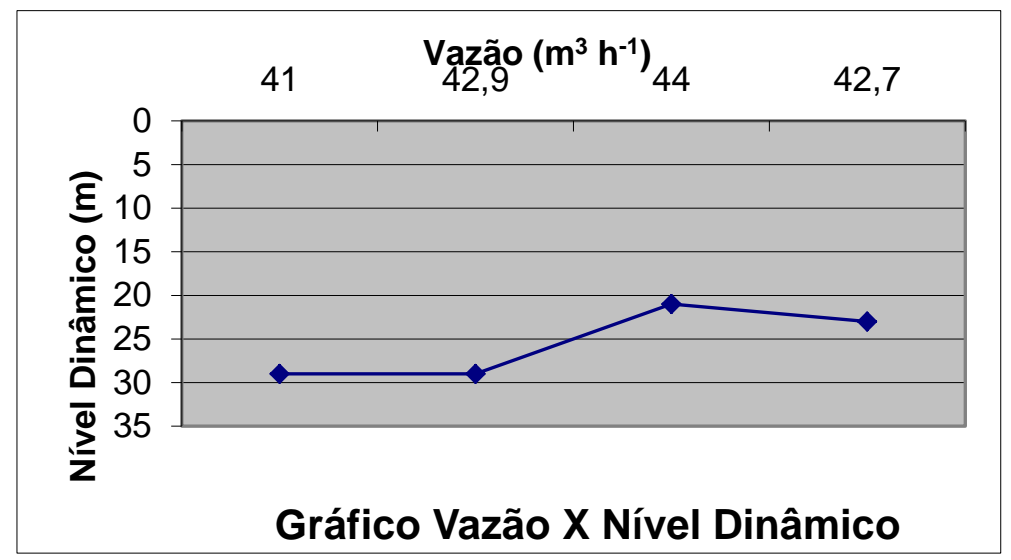

\begin{tabular}{|r|r|r|}
\hline \multicolumn{3}{|c|}{ Poço no Bairro Monte Verde } \\
\hline ND (m) & $\mathbf{Q}\left(\mathbf{m}^{\mathbf{3}} \mathbf{h}^{-\mathbf{1}}\right)$ & \multicolumn{1}{c|}{ DATA } \\
\hline 29 & 41 & $08 / 07 / 1975$ \\
\hline 29 & 42,9 & $05 / 09 / 2010$ \\
\hline 21 & 44 & 2011 \\
\hline 23 & 42,7 & 2012 \\
\hline
\end{tabular}

Figura 6: Gráfico de nível dinâmico versus vazão, de poço perfurado em 1975. 
5) Aumento de nitrato em dois poços da Formação Serra Geral: foi detectado um aumento de nitrato ultrapassando os valores máximos permitidos pelo Resolução 396, de 2008, do Conselho Nacional do Meio Ambiente (CONAMA), fazendo com que houvesse a desativação do poço.

6) Acompanhamento dos chamados poções: com a manutenção de valores constantes de vazões específicas ao longo dos anos.

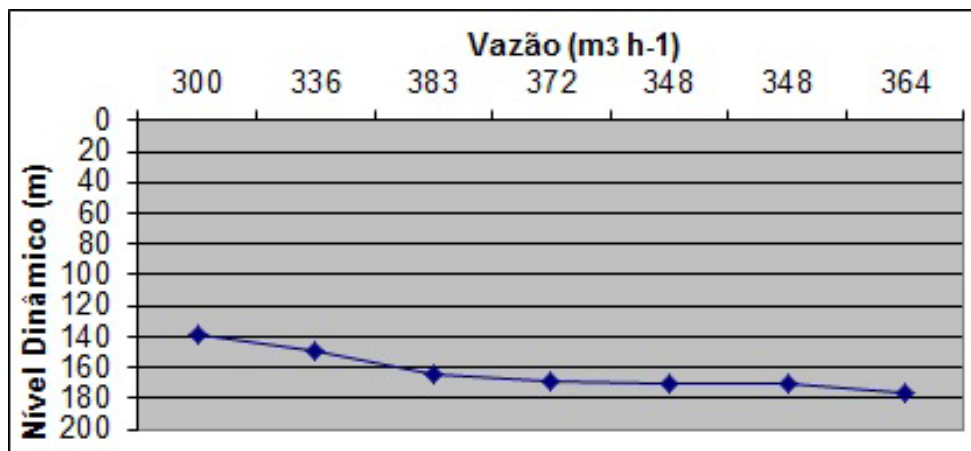

\begin{tabular}{|c|c|c|}
$\mathbf{N D}(\mathbf{m})$ & $\mathbf{Q}(\mathbf{m} 3 \mathbf{h}-\mathbf{1})$ & DATA \\
\hline 138 & 300 & 1994 \\
\hline 149 & 336 & 2003 \\
\hline 165 & 383 & 2008 \\
\hline 169,6 & 372 & 2009 \\
\hline 170,5 & 348 & 2010 \\
\hline 170 & 348 & 2011 \\
\hline 176 & 364 & 2012 \\
\hline
\end{tabular}

Gráfico de Vazão X Nivel Dinâmico

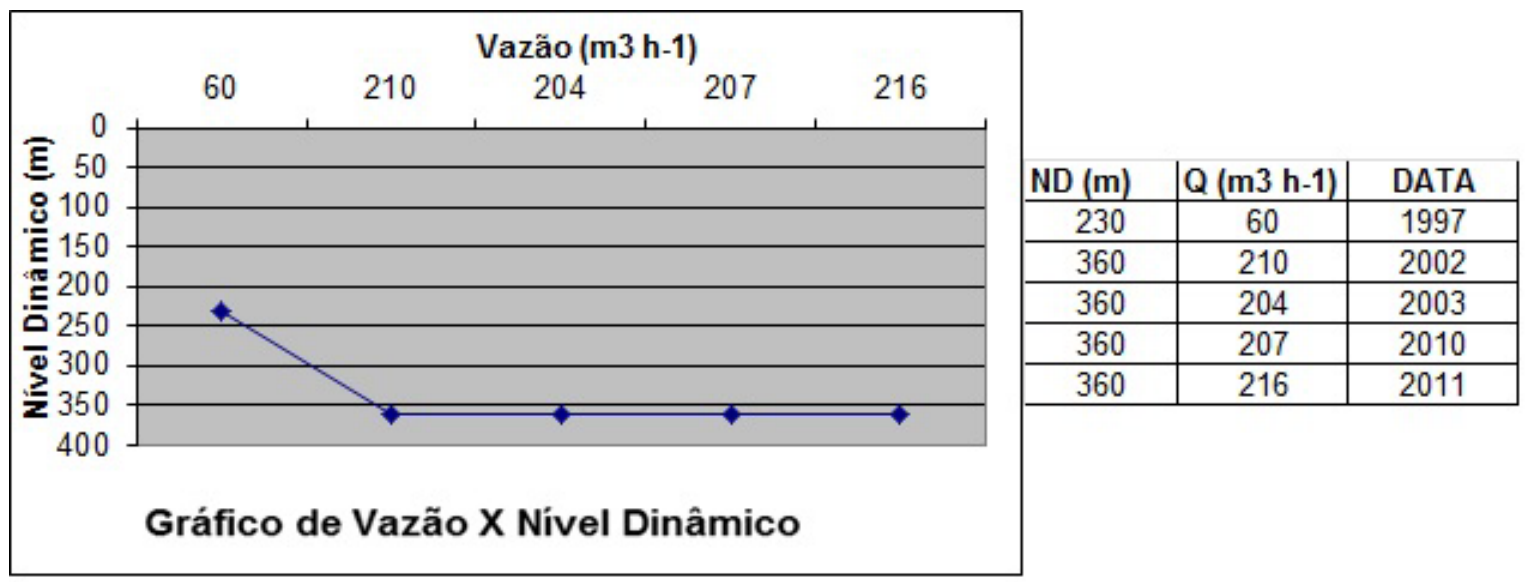

Figura 7: Gráfico de nível dinâmico versus vazão de poções perfurados no ano de 1994 no bairro Pioneira e 1997 no bairro Coophasul.

\section{7- DISCUSSÕES E CONCLUSÕES}

Com base nos dados apresentados podemos concluir:

1) O monitoramento preventivo de poços realiza medições elétricas dos parâmetros das bombas submersas. Essas medições, além de indicar um problema de desgaste natural do conjunto moto-bomba submerso, podem alterar-se devido a carreamento e produção de 
areia no poço. Com o monitoramento pode-se detectar o problema no início, visando o reparo e maior vida útil, tanto da bomba quanto do poço.

2) O monitoramento de profundidades de níveis estático e dinâmico, associado a vazão de produção do poço deve ser constante. Qualquer anomalia deve ser avaliada, visando conter rebaixamentos expressivos dos sistemas aquíferos e o bom funcionamento do poço.

3) A contaminação por nitrato, detectada na água bruta de produção do poço, deve ser observada e o poço deve parar o funcionamento, devido ao não atendimento da Resolução 396 do CONAMA. Alternativas para contenção de nitrato ainda são muito onerosas, assim, a desativação do poço é a alternativa mais utilizada.

4) Além do nitrato, parâmetros físico químicos como $\mathrm{pH}$, manganês e ferro devem ser observados. O manganês e ferro acabam por alterar o sabor e cor da água, tornando-a não apreciada para consumo e fazendo com que haja reclamações da população, mesmo em teores contidos na Resolução 396 do CONAMA. Além disso, posteriormente, as concentrações de cloreto, sólidos totais dissolvidos, assim como nitrato, podem ser úteis para uma análise mais detalhada (escala local), assim como, associadas a espacialização e zoneamento desses resultados através de mapas hidroquímicos do município (escala regional).

A responsabilidade do gerenciamento das águas subterrâneas compete ao estado, conforme a constituição federal de 1988, em seu artigo 26, que “inclui como bens do estado: I - as águas superficiais ou subterrâneas, fluentes, emergentes e em depósito. Completando, a Lei Federal $\mathrm{n}^{\circ}$ 9.433, de 8 de janeiro de 1997, que institui a política nacional de recursos hídricos tem como premissa básica os seguintes fundamentos: I - a água é um bem de domínio público; II - a água é um recurso natural limitado,com valor econômico; III- em situações de escassez, o uso prioritário é para consumo humano e dessendentação animal. Com isso, podemos concluir que o monitoramento preventivo das águas subterrâneas deve ser mais difundido e mostrada sua devida importância. Somente através desse monitoramento pode-se entender as particularidades de cada sistema aquífero, visando também o cumprimento da legislação sobre águas subterrâneas.

\section{8- REFERÊNCIAS BIBLIOGRÁFICAS}

BRASIL. Constituição (1988). Constituição da República Federativa do Brasil. Brasília, DF: Senado, 1988. 
BRASIL. Lei Federal n. 9.433, de 08 de janeiro de 1997. Brasília-DF: Assembléia Legislativa. 1997.

BRASIL. Resolução CONAMA nº 396, 03 de Abril de 2008. Dispõe sobre a classificação e diretrizes ambientais para o enquadramento das águas subterrâneas e dá outras providências., Brasília, DF, Publicada no DOU nº 66, de 7 de abril de 2008, Seção 1, páginas 64-68.

CPRM - Serviço Geológico do Brasil. Mapa Geológico do Mato Grosso do Sul, escala 1:1.000.000. Brasília, CPRM, 2006.

FERNANDES, L. A.; COIMBRA, A. M. A cobertura cretácea suprabasáltica no Estado do Paraná e Pontal do Paranapanema (SP): os grupos Bauru e Caiuá. 37 Congresso Brasileiro de Geologia. São Paulo: Sociedade Brasileira de Geologia. 2: 506-508 p. 1992.

A Bacia Bauru (Cretáceo Superior, Brasil). Anais da Academia Brasileira de Ciências, v. 68, n. 2, p. 195-205, 1996.

FÚlfaro, V. J.; PerinotTO, J. A. J. A Bacia Bauru: Estado da Arte. 4 Simpósio sobre o Cretáceo do Brasil. Rio Claro: Universidade Estadual Paulista: 297-303 p. 1996.

MENEGAZZO, M.C.; Sedimentação da Bacia Bauru: cenário tectônico, idade dos depósitos e ambientes paleodeposicionais. 292 p. Tese de Doutorado - Instituto de Geociências e Ciências Exatas, Universidade Estadual Paulista, Rio Claro, 2016.

MENEGAZZO, M. C.; CATUNEANU, O.; CHANG, H. K. The South American retroarc foreland system: The development of the Bauru Basin in the back-bulge province. Marine and Petroleum Geology, n. 73, p. 131-156, 2016.

MILANI, E. J. et al. Bacia do Paraná. Boletim de Geociências da Petrobras, v. 15, n. 2, p. 265-287, 2007.

Bacias Sedimentares Brasileiras - Cartas Estratigráficas. Boletim de Geociências da Petrobras, v. 15, n. 2, p. Anexo, 2007. 
. Revisão estratigráfica da parte Oriental da Bacia Bauru (Neo-Cretáceo). Revista Brasileira de Geociências v. 30, n. 4, p. 717-728, 2000.

RICCOMINI, C. Arcabouço estrutural e aspectos do tectonismo gerador e deformador da Bacia Bauru no Estado de São Paulo. Revista Brasileira de Geociências, v. 27, n. 2, p. 153-162, 1997a.

. Considerações sobre a posição estratigráfica e tectonismo deformador da Formação Itaqueri na porção centro-leste do Estado de São Paulo. Revista do Instituto de Geociências, v. 18, n. 1/2, p. 41-48, $1997 \mathrm{~b}$. 